\title{
Business Process Management in Linking Enterprise Information Technology in Companies of Agricultural Sector
}

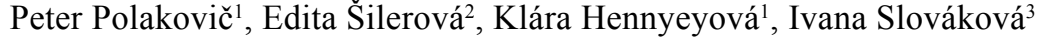 \\ ${ }^{1}$ Department of Informatics, Faculty of Economics and Management, Slovak University of Agriculture \\ in Nitra, Slovak Republic \\ ${ }^{2}$ Department of Infortation Technologies, Faculty of Economics and Management, Czech University of Life \\ Sciences in Prague, Czech Republic \\ ${ }^{3}$ Institute of Foreign Languages, Technical University in Zvolen, Slovak Republic
}

\begin{abstract}
Business Process Management is one of the most important components of a process-driven organization that we perceive as a sum of processes that are more or less follow-up. By adjusting and managing these processes, we can greatly influence the organization's performance, efficiency, flexibility and competitiveness. Business Process Management is important to support the technical infrastructure of modern information systems and communication technologies. These systems are part of the overall enterprise information system. The following article focuses on information and communication technologies for the proper and efficient functioning of process management in agro sectoral companies. This article presents a summary of theoretical knowledge and practical recommendations for creating and maintaining a process management system in enterprises with the support of information and communication technologies. For a more detailed analysis of this issue, statistical research, the partial results of which are subjected to statistical testing, are presented in the following article.
\end{abstract}

\section{Keywords}

Business process management, enterprise information systems, business infrastructure, process management.

Polakovič, P., Šilerová, E., Hennyeyová, K. and Slováková, I. (2018) "Business Process Management in Linking Enterprise Information Technology in Companies of Agricultural Sector", AGRIS on-line Papers in Economics and Informatics, Vol. 10, No. 3, pp. 119-126. ISSN 1804-1930. DOI 10.7160/aol.2018.100310.

\section{Introduction}

Nowadays, information and communication technologies (ICT) are an increasingly important factor in supporting the achievement of corporate goals (Host'ovecký et al., 2015). The development of information and communication technologies leads the company to process electronic documents more and more (Tvrdíková, 2008). ICT becomes an element that enables growth and development of an organization. This is why ICT demands are rising. Gradual developments have shown that ICT helps create value where it enables business processes to be supported by making profits in the technology and business parts of the enterprise (Hallová et al., 2017). In general, an ICT value for an enterprise can be viewed from an analytical or pragmatic point of view. It is a problem for many companies to link the ICT with their strategic interests and daily routines (Vaněk et al., 2011).
In order for an organization to function effectively, it must identify and manage a number of related activities. The application of the process system within the organization along with process identification and interaction, as well as their management, can be seen as a process approach (McAdam, 2003). According to Ringim et al., (2012) is the ability to innovate and change to become a necessary competitive weapon, closely linked to the knowledge potential of the organization and the ability of an organization to learn. The basic principle is the collective effort to achieve the desired, shared goal by increasing the team's action potential in the process of personal and team learning. The essence of enhancing the action potential is to be able to respond based on acquired knowledge and to develop solutions (Carda et al., 2001).

We can see each enterprise as a system of processes, activities, and activities to achieve the goals. They 
differ with each other, in particular, in how and how effective the individual processes are performed, respectively. as they are managed ( ̌ epa, 2012). Process management is defined as a methodology for evaluating, analyzing and improving key business processes, based on customer needs and requirements. An interesting basis for understanding the procedural approach is systemic theory, which emphasizes the necessity of a comprehensive understanding of the partial management processes and their coordinated alignment in the target behavior of an integrated functioning unit. The advantage of these approaches is that they are based on the abstraction of reality on a set of elements and their linkages. They also try to identify inputs to the system that are essential to the behavior of the system so that the system achieves a goal (Ahmad et al., 2007).

Process Management and Business Process Management (BPM) are the most common terms in today's business and ICT world. Process management is a natural and comprehensive management approach to business creation, creating the prerequisites for a highly efficient, agile, innovative and adaptable organization that far exceeds the reachable by traditional management approaches (Smith, 2003). The aim of the article is to analyze the use of information systems infrastructure and technologies in agribusinesses in connection with process management, and to describe their dependencies on the basis of a questionnaire survey of agriculture companies sample. With processes we meet today at almost every step. The most popular is this term in companies, corporations that are moving in the area of information systems and technologies. When it sometimes appears that processes and information technologies are the same, which of course is not the case. However, the real nature of IT governance is very much supported. The word process can be used almost anytime, anywhere in any meaning.

According to Luftman (2003) process management is an activity leading to the transformation of a functionally oriented organization into a processbased organization. The process of implementing a process organization requires personnel and project security. Task solving with such a high degree of abstraction and complexity in an organization's heterogeneous ICT infrastructure environment must support appropriate ICT technologies. A technology cluster created within the organization from a variety of non-interconnected software products, which aims to cover the whole area of process design, process implementation, implementation, and tracking, does not need to meet the expectations of the organization effectively. Zairi et al., (1995) says that procedural management means a substantial change in the notion of the information system over the traditional view. The arrival of the process management terminated the concepts of the information system as a non-monolithic monolith with a given structure, determined by a properly designed database and its associated functionality.

Process management requires that the information system is flexibly adapted to the business process, because its only purpose is to support it. Business processes, however, naturally change. This has a significant impact, for example, on the concept of information system standardization, as is known from the ERP, whose concept has traditionally led to a single, universal, definitive solution, generally applicable to each organization. This concept is overcoming today, precisely in the context of knowledge that has brought about process management ideas, as evidenced by SAP's approach, the market leader in systems in this area. In the past, it has come up with the new SAP Net Weaver product, meaning a significant conceptual turn in the concept of ERP by this company (Crowe, 2002).

The requirements of the organization's process system for its information system are as follows (Ozcelik, 2010):

- The information system must, as far as possible, support all activities of business processes, that is to say they have to be covered by their functionality,

- The information system must support the management of the business processes of the workflow process, so it must enable the processes to be monitored during the process and the process,

- The information system must, as far as possible, support all the patterns of the business in question, so it must, by its function, be assisted by the process of respecting as far as possible all the restrictions and rules of the business,

- The information system must enable the natural transformation of business processes, so it cannot prevent its conceptual or other changes in its structure. 
While the data stored in the information system database represents its information potential (about the facts of the corporate system and its contexts), its functionality represents an action potential (the ability to process data). The workflow management system then has the role of a link between the data and the functions of the system, which also allows the enterprise process to use its system data through its functions (Dennis et al., 2003). The process-managed organization information system differs from the traditional one by separating the functions of the system from the way they are used. The functionality of the system for him represents the net potential of information support for activities, which is maximally universal, and therefore independent of the particular use procedure. While the functions of the system - the support of routine activities from processes are basically relatively unchanging, standard, their combining is always specific, each time given by a particular situation. The procedure for using system features is always given by the current business processes. Therefore, a process-managed organization can not suffice with a traditional information system, because it preserves some form of procedures by encoding them into functionality and thus makes business processes virtually immobilized (Mouzas, 2006). If an organization is to become dynamic, naturally variable through its diverse business processes, its infrastructure must also support this variability. Instead of frozen practices for the use of their functions, they must support their eventual combinability according to the ever changing needs of processes (Vaněk, 2009; Landa, 2010).

The main trend in the further development of the BPM segment is SOA (Service Oriented Architecture). BPM solutions are a key component of service-oriented architecture. They represent the top layer of the architecture that organizes the implementation of various services in the sense of progressive implementation of the individual steps of the business process. BPM solutions must be closely interconnected with other software components of SOA implementations such as Enterprise Servis Bus (ESB), SOA lifecycle management solutions, service register, and so on (Ozcelik, 2010). The reported BPM solution development confirms the trend of BPM connectivity with SOA. Business Process Management solutions help design, deploy, implement and track business processes. They allow the organization of individual partial automatic or manual operations according to the requirements of a complex business process. They manage the execution of processes within rules that are derived from valid legislation, standards, and organization guidelines. They support the integration of applications and services into the organization's information system. Customize process execution to business requirements and track the current state of execution of processes. According to Ahmad et al., 2007, the benefits of implementing BPM technology into the corporate IS environment is to improve the organization's ability to cope with business-related requirements and opportunities. Organizations must flexibly respond to environmental changes to maintain their market position. Flexible customization of custom business processes, strategies, needs, services or products varies with customer, partner, and regulator requirements. Most changes require changes in the IT structure of the organization. The ability to flexibly change the information system is therefore a major constraint in implementing process changes resulting from the need to cope with organizational requirements and opportunities (Porter et al., 1993). BPM solutions enable fast change of IT infrastructure related to business process modeling. BPM solutions enable one group of tools to capture processes from a business perspective and then link them to the IT applications that are necessary to implement them.

BPM sets of software packages include a set of software tools for the entire process development cycle, from design to monitoring of real-world processes. Their approach eliminates the repetition of the standard deficiencies of the current process analysis, to the maximum extent linked to process and application analysis, the related processes and roles are defined and documented in a structured manner. There is no difference between what has been proposed and applied in practice. BPM has a very wide-ranging application due to the provided process modeling capabilities and to cover the entire development cycle. It provides efficient tools for process modeling by providing the benefits of EAM (Enterprise Application Integration), EAM (Enterprise Architecture Modeling). BPM technology is a general platform in terms of independence from the vertical line of business or the type of organization (Rěpa, 2012; Ahmad et al., 2007). Introducing BPM is the most important prerequisite for the successful operation and advancement of any type of organization. BPM allows not only to analyze and monitor processes but, above all, 
to target, organizationally and efficiently to reveal new opportunities for organizational improvement (Mouzas, 2006; Tvrdíková, 2008).

\section{Material and methods}

In 2017, the Department of Computer Science conducted a survey focused on the issue of Process Management in agro-business enterprises. The thesis focuses on the analysis of the use of process management in connection with the infrastructure of enterprise information technologies and systems. Hence, the following hypotheses also seek to clarify the main patterns and links in contemporary businesses. Based on the main goal of the thesis, we have formulated the following hypotheses.

H1: The use of process management in enterprises depends mainly on the amount of annual turnover than on the size of the enterprise by number of employees.

H2: Companies with implemented process management use a significantly different set of software as enterprises that do not use process management.

A survey of enterprises was made up of 51 agrosector enterprises focused on agriculture and food. Several scientific methods have been used in the survey. The main method was the analysis and comparison, which, based on the questionnaire survey, identified the current situation and the current state of use of BPM and information infrastructure in practice. We used the synthesis method to process the knowledge from the literature. We have applied the induction method to formulate conclusions based on the evaluation of the survey. Using the deduction method, we have applied the lessons learned from the literature to draw conclusions. To find the data for our analysis, we chose a questionnaire survey, which was distributed to individual entities. Statistical calculations were made by SPSS Statistics. The questionnaire, through its results, was textured to the reliability of its construct. Analysis of selected parts of the survey was performed in the SPSS IMB statistical software. Reliability was tested by Cronbach's Alpha. Cronbach's Alpha is one of the most frequently used indexes for investigating the reliability of a measuring tool (questionnaire). Based on the structure of the questionnaire and the results obtained:

$\alpha=(\mathrm{k} /(\mathrm{k}-1) *[1-\Sigma(\mathrm{s} 2 \mathrm{i}) / \mathrm{s} 2 \mathrm{sum}]$, where $\mathrm{k}$ - number of items (number of questions, quality criteria)

$\mathrm{s} 2 \mathrm{i}$ - variance for the items

s2sum - variance for the sum of items

Several statistical methods have been used for statistical evaluation. Verification of dependencies between the examined characters was performed using the Chi-quadrate test $\left(\chi^{2}\right)$, respectively $\left(\chi^{2}\right)$ - square contingency. This test consists of a comparison of empirical and theoretical abilities, from. what would be empirical abilities if the characters were independent. For statistical tests where the Chi-quadrate independence test could not be used because the cell count assumption in the contingency table was not followed, Fisher's exact test was used. Fisher's exact test is based on a contingency table and verifies the null hypothesis of the equality of two shares, i.e. the independence of the two binary variables. This test is based on the assumption that all marginal frequencies (row totals / columns) in the pivot table are fixed. This assumption is rarely met. Typically, only line counts or only total abundance are fixed.

\section{Results and discussion}

The benchmark sample consisted of 8 small enterprises, 33 medium-sized enterprises and 10 large enterprises. In the survey, we focused mainly on enterprises that implement modern information systems and management methods, so we focus mainly on large and medium-sized businesses that usually have to deal with this issue first, have more extensive experience, and have generally come to a halt in implementation. In the following part, we focus on the analysis of the use of modern management methods and IS / IT infrastructure in enterprises, the existence or absence of elaboration of strategies, concepts, whether using different management tools and methods but also information technology as a supporting mechanism in management. We also explore the use of IT and software in companies. In the survey, we analyzed the existence of plans and strategies for business areas and the use of different management methods. With the greatest percentage of occurrence and workmanship, the main strategies, strategic goals, visions and missions are found in enterprises. Secondly, there are established performance measurement systems and enterprise benchmarking, mostly for large companies. For small businesses, percentages are down towards other groups, but they are held with more than 
half of the sample examined. Managerial methods and techniques are listed in the Table 1.

When deciding on implementing a new enterprise information system, or upgrading or completing the current functionality, businesses are considering a number of criteria that will require the selection of this IS / IT facility. On the occasion of conducting our survey in companies and organizations of various sizes, we have included this assessment in the survey as well. We've offered the manager a choice and evaluation, which criteria are the most common in their organizations. The report is created based on the size of the business, and therefore the individual percentages are calculated as the average value of the weights that the respondents have assigned within one enterprise size group - Table 2.

In the next section, we present the results of the questions on the most important areas of business processes in IS / IT implementation or innovation. It is not just the areas that IS / IT implementation is most affected, but it is also areas that affect implementation itself, its superior or even the controlling element. The survey was closed by a selection of options. The interviewed managers could first see all areas or processes, then consider whether they were in IS / IT implementation in their company and most of them checked that they were. Therefore, this report is only informative, and we have used it to sort business processes according to the significance attributed to them by the practice managers - Table 3 .

The survey focuses on analyzing the use of process management in linking to existing enterprise information technology and systems infrastructure. Hence, the hypotheses set by us are intended to clarify the main patterns and relationships in today's businesses. Among

\begin{tabular}{|l|c|c|c|}
\hline Organization & Small enterprises & Medium-sized enterprises & Large enterprises \\
\hline $\begin{array}{l}\text { Introduced and standardized project management } \\
\text { methodology }\end{array}$ & $6.1 \%$ & $22.7 \%$ & $45.3 \%$ \\
\hline Developed strategic plan at the level of functional areas & $26.4 \%$ & $56.5 \%$ & $64.2 \%$ \\
\hline Introduced graphical model of processes & $3.3 \%$ & $11.7 \%$ & $27.9 \%$ \\
\hline Established process management & $24.6 \%$ & $40.3 \%$ & $56.1 \%$ \\
\hline
\end{tabular}

Source: own research and processing

Table 1: Overview of the introduction and use of management methods and techniques.

\begin{tabular}{|l|c|c|c|}
\hline Organization & Small enterprises & Medium-sized enterprises & Large enterprises \\
\hline Software Compatibility & $65.6 \%$ & $71.6 \%$ & $75.0 \%$ \\
\hline Software functionality & $88.7 \%$ & $89.8 \%$ & $89.6 \%$ \\
\hline Software price & $78.7 \%$ & $75.6 \%$ & $67.0 \%$ \\
\hline Software extensibility & $56.7 \%$ & $67.9 \%$ & $94.8 \%$ \\
\hline Software availability in SK language & $94.5 \%$ & $90.0 \%$ & $78.4 \%$ \\
\hline Local support availability & $87.0 \%$ & $80.7 \%$ & $78.9 \%$ \\
\hline Software editing & $60.3 \%$ & $76.0 \%$ & $87.1 \%$ \\
\hline
\end{tabular}

Source: own research and processing

Table 2: Criteria for selecting management software or business system.

\begin{tabular}{|l|c|c|c|}
\hline Organization & Small enterprises & Medium-sized enterprises & Large enterprises \\
\hline Analysis of product sales & $63.6 \%$ & $68.6 \%$ & $67.0 \%$ \\
\hline Budgeting & $69.7 \%$ & $75.8 \%$ & $85.6 \%$ \\
\hline Human Resources & $89.7 \%$ & $80.6 \%$ & $91.0 \%$ \\
\hline Marketing & $84.7 \%$ & $87.9 \%$ & $87.8 \%$ \\
\hline Inventory management & $52.1 \%$ & $55.3 \%$ & $56.0 \%$ \\
\hline Financial analysis & $74.7 \%$ & $76.2 \%$ & $80.9 \%$ \\
\hline
\end{tabular}

Source: own research and processing

Table 3: Areas of Business Process Changes in IS / IT Implementation and Innovation. 
the businesses we have analyzed, we have selected only the ones that surveyed to use, in part, the process management, its tools, or have it fully implemented. The breakdown of enterprises into groups by number of employees is similar to the overall distribution of enterprises across the sample. However, when we look at the breakdown by turnover, there is a significant non-proportionality, $46 \%$ of process -managed enterprises being enterprises with a turnover of more than EUR 3.5 million. It follows that companies apply procedural management mainly because of work, that is, to better manage the burden of activity that we can monitor by dependence on the amount of turnover, rather than on the size of the number of employees. We can also evaluate that a process-managed enterprise is at a higher level of management, that is, it has the necessary skills needed for successful growth, as well as the strategy and strategic goals of the company, the established performance measurement system and, in particular, targeted IT / IT infrastructure management. So we can say that hypothesis 1 has been confirmed. Businesses can target there IS / IT investments effectively and aiming to maximize the resulting effect reflecting their benefits, to automate and modernize their processes, or to postpone, save, expose, intuitively, and sometimes inadvertently or impulsively, and mitigate for their inadequate result. We believe that if a company is process-driven, that is, at a higher level of management, it should know how to help with technology and purposefully and purposefully invest its resources. Under hypothesis 2, spending is remarkable for small and medium-sized enterprises that use process management up to $45.6 \%$. This means that small and medium enterprises using process management spend more than twice as much funding on IS / IT as enterprises that are not process-driven. Thus, in the case of small and medium-sized enterprises, we assess that this hypothesis is confirmed.

\section{Conclusion}

At the time of the arrival of BPM from theory into practice, there were also certain exaggerated expectations. Particularly in smaller organizations, they welcomed the abandonment of traditional organizational structures and functional systems, and expected procedural management to have some management release and automatic ability to quickly adapt to changing conditions and improvement. Ciccio (2015) argues that adapting to new conditions, takes some time to ensure that integrated systems deliver the expected results. As is also the case with habit technology, the human dimension is the cornerstone of an accident. It is critical, and everything that is well thought out and planned can go wrong. While we can use engineering approaches, we must count on it, oftentimes on the illogical resistance of workers, not to try new things, even if they later save their jobs, time and performance. Therefore, the human dimension becomes a decisive factor, mainly human motivation and education. The process view requires the need to find a superior reason for the activities we perform in such a way that it is independent of the rules of operation of individual business objects. It is argued that for every business process there must be some reason in the form of purpose, purpose, and eventually also external impetus. Then we get the shifts that are important for modeling the enterprise information system. In business processes, it is essential that the outcome of the process is a product or service that is directed to a customer, predominantly external, but also within an enterprise. As a result of the process management process, the executive team's proposal is to organize the company so that the key processes that are important for competitiveness are effectively implemented and meet the expectations of both internal and external customers. After accepting the proposal by the company, the processes are introduced into the routine running of the company. The benefits of process management depend on the objectives of the project. As we have already said, the way we design processes and therefore the benefits can be influenced by the goals.

However, process management gives a fresh insight into the importance of the activities carried out and helps to better define the concrete responsibilities for their implementation and quality. Distorting the traditional line structure and placing emphasis on results and totals, not on parts. So we pay attention to the process across the organizational structure, contributing to better teamwork and corporate culture (Aalst et al., 2016). 
Corresponding authors:

PaedDr. Peter Polakovič, Ph.D.

Department of Informatics, Faculty of Economics and Management

Slovak University of Agriculture, Tr. A. Hlinku 2, Nitra, 949 01, Slovak Republic

E-mail:peter.polakovic@uniag.sk

\section{References}

[1] van der Aalst W. M. P., La Rosa, M. P. and Santoro, F. M. (2016) " Business Process Management", Business and Information Systems Engineering, Vol. 58, No. 1. pp. 1-6. E-ISSN 1867-0202, ISSN 2363-7005. DOI 10.1007/s12599-015-0409-x.

[2] Ahmad, H. Francis, A. and Zairi, M. (2007) "Business process reengineering: Critical success factors in higher education", Business Process Management Journal, Vol. 13, No. 3, pp. 451-469. ISSN 1463-7154. DOI 10.1108/14637150710752344.

[3] Carda, A. and Kunstová, R. (2001) "Workflow, řízení firemních procesư" (In Czech), Grada Publishing, 136 p. ISBN 80-247-0200-2.

[4] Ciccio, C. (2015) "Knowledge - Intensive Processes: Characteristics, Requirements and Analysis of Contemporary Approaches", Journal on Data Semantics, Vol. 4, No. 2. pp. 29-57. ISSN 1861-2032 29-57.

[5] Crowe, T. J., Fong, P. M, Bauman, T. A. and Zayas-Castro, J. L. (2002) "Quantitative risk level estimation of business process reengineering efforts", Business Process Management Journal, Vol. 8, No. 5, pp. 490-511. ISSN 1463-7154. DOI 10.1108/14637150210449148.

[6] Dennis, A., Carte, T. and Kelly, G. (2003) "Breaking the rules: success and failure in groupwaresupported business process reengineering”, Decision Support Systems, Vol. 36, No. 2, pp. 31-47. ISSN 2050-6996. DOI 10.1016/S0167-9236(02)00132-X.

[7] Hallová, M., Polakovič, P., and Slováková, I. (2017) "Current Trends in Training of Managers in the Field of Information and Communication Technologies and identifying the barriers to education of managers", AGRIS on-line Papers in Economics and Informatics, Vol. 9, No. 4, pp. 45-52. ISSN 1804-1930. DOI 10.7160/aol.2017.090405.

[8] Host’ovecký, M., Mišút, M. and Pribilová, K. (2015) "Web based testing in science education". In "Innovations and advances in computing, informatics, systems sciences, networking and engineering: lecture notes in electrical engineering", CISSE 2013 virtual conference, Springer international publishing, Vol. 313, pp. 247-254. ISBN 978-3-319-06772-8. ISSN 1876-1100.

[9] Landa, O. (2010) "Jakou roli ve strategii dnes hraje HR?“ (in Czech), Human Resources Management, Vol. 6, No. 9, pp. 231-300. ISSN 1801-4690.

[10] Luftman, J. (2003) "Assessing It/Business Alignment, Information Systems“, Management, Vol. 3, No. 4, pp. 9-15, ISSN 1846-3363. DOI 10.1201/1078/43647.20.4.20030901/77287.2.

[11] McAdam, R. (2003) "Radical Change: A Conceptual Model for Research Agendas", Leadership \& Organization Development Journal, Vol. 24, No. 4, pp. 226-35. ISSN 0143-7739. DOI 10.1108/01437730310478093

[12] Mouzas, S. (2006) "Efficiency versus Effectiveness in Business Networks", Journal Of Business Research, Vol. 59, No. 10, pp. 1124-1132. ISSN 0148-2963. DOI 10.1016/j.jbusres.2006.09.018.

[13] Ozcelik, Y. (2010) "Do business process reengineering projects payoff?", International Journal of Project Management, Vol. 28, No. 1, pp. 7-13. ISSN 0263-7863. DOI 10.1016/j. ijproman.2009.03.004.

[14] Porter, L. J. and Parker, A. J. (1993) "Total quality management - the critical success factors", Total Quality Management, Vol. 4, No. 1, pp. 13-22. ISSN 1360-0613. DOI 10.1080/09544129300000003. 
[15] Ringim, K. J., Razalli, M. R. and Hasnan, N. (2012) "Critical Success Factors for Business Process Management for Small and Medium Banks in Nigeria”, Business And Management Review, Vol. 2, No. 1, pp. 83-91. ISSN 2047-0398.

[16] Řepa, V. (2012) "Procesně ř́zená organizace" (In Czech), Grada Publishing, 304 p. ISBN 978-80-247-4128-4.

[17] Smith, M. (2003) "Business process design: correlates of success and failure", The Quality Management Journal, Vol. 10, No. 2, pp. 38-49. ISSN 10686967. DOI 10.1080/10686967.2003.11919062.

[18] Tvrdíková, M. (2008) "Aplikace moderních informačních technologii v řizení firmy". Grada Publishing, 176 p. ISBN 978-80-247-2728-8.

[19] Vaněk, J. Jarolímek, J. and Šimek, P. (2009) "Information Services and ICT Development in Agriculture of the Czech Republic", AGRISon-line Papers in Economics and Informatics, Vol. 1, No. 1, pp. 47-52. ISSN 1804-1930.

[20] Vaněk, J., Jarolímek, J. and Vogeltanzová, T. (2011) "Information and Communication Technologiesfor Regional Development in the Czech Republic - Broadband Connectivity in Rural Areas", AGRISon-line Papers in Economics and Informatics, Vol. 3, No. 3, pp. 67-76. ISSN 1804-1930.

[21] Zairi, M. and Sinclair, D. (1995) "Business process re-engineering and process management", Business Process Management Journal, Vol. 1, No. 1, pp. 161-173. ISSN 1463-7154. DOI 10.1108/14637159510798248. 